\title{
Pharmacokinetics of Ertapenem in Colorectal Tissue
}

\author{
M. Wittau ${ }^{\text {a }} \quad$ J.Scheele ${ }^{a} \quad$ J.B. Bulitta ${ }^{\text {e }} \quad$ B. Mayer ${ }^{\text {b }} \quad$ V. Kaever ${ }^{c} \quad$ H. Burhenne ${ }^{c}$ \\ D. Henne-Bruns ${ }^{a}$ R. Isenmann ${ }^{d}$ C. Brockschmidt ${ }^{a}$ \\ Departments of a Visceral Surgery and ${ }^{b}$ Biometry, University of Ulm, Ulm, 'Institute of Pharmacology, Hannover \\ Medical School, Hannover, and ${ }^{\mathrm{d}}$ Department of Visceral Surgery, St. Anna Virngrundklinik, Ellwangen, Germany; \\ ${ }^{e}$ Centre for Medicine Use and Safety, Faculty of Pharmacy and Pharmaceutical Sciences, Monash University, \\ Melbourne, Vic., Australia
}

\section{Key Words}

Pharmacokinetics • Carbapenem • Tissue penetration • Ertapenem

\begin{abstract}
Background: There are only limited data on tissue kinetics of ertapenem in colorectal tissue more than $3 \mathrm{~h}$ after administration of the drug. The purpose of this study was to assess the pharmacokinetics (PK) of ertapenem in colorectal tissue via population PK modeling. Patients and Methods: Patients $\geq 18$ years requiring surgical intervention at the colon and/or rectum were eligible (ClinicalTrials.gov identifier: NCT 00535652). Tissue and blood samples were taken during surgery after a single dose of $1 \mathrm{~g}$ ertapenem. Ertapenem concentration was determined by high-performance liquid chromatography/mass spectrometry. Population PK modeling was performed in S-ADAPT. Results: Twenty-three patients were enrolled. The highest tissue concentration was $6.4 \pm 2.3 \mathrm{mg} / \mathrm{kg}$, the highest total plasma concentration $51.34 \pm 9.4 \mathrm{mg} / \mathrm{l}$, the highest unbound plasma concentration $7.05 \pm 1.1 \mathrm{mg} / \mathrm{l}$, and the unbound fraction in plasma was 14-15\% for total ertapenem concentrations below approximately $22 \mathrm{mg} / \mathrm{l}, 19 \%$ at $100 \mathrm{mg} / \mathrm{l}$, and $25 \%$ at $250 \mathrm{mg} / \mathrm{l}$. The
\end{abstract}

estimated geometric mean terminal half-life was $2.5 \mathrm{~h}$ for plasma and tissue. In the Monte Carlo simulation, a single dose of $1,000 \mathrm{mg}$ ertapenem achieved robust ( $\geq 90 \%$ ) probabilities of target attainment up to a minimum inhibitory concentration (MIC) of approximately $2 \mathrm{mg} / \mathrm{l}$ for the bacteriostasis target (free time above $\mathrm{MIC}, f \mathrm{~T}_{>\mathrm{MIC}}=20 \%$ ) and up to $0.25-0.5 \mathrm{mg} / \mathrm{l}$ for the near-maximal killing target $(40 \%$ $f \mathrm{~T}_{>\mathrm{MIC}}$ ). Conclusion: Our data indicate an adequate penetration of ertapenem into uninfected colorectal tissue up to $8.5 \mathrm{~h}$ (35\% of the dosing interval) after administration of $1 \mathrm{~g}$ intravenously.

Copyright $\odot 2011$ S. Karger AG, Basel

\section{Introduction}

The treatment of serious bacterial infections often requires parenteral antibiotic therapy. Carbapenems are among the most potent antimicrobial agents currently available. They are usually assigned for the treatment of serious infections or multidrug-resistant pathogens, al-

M.W. and J.S. contributed equally to this work.

\section{KARGER}

Fax +41613061234 E-Mail karger@karger.ch www.karger.com
(C) 2011 S. Karger AG, Basel 0009-3157/11/0575-0437\$38.00/0

Accessible online at: www.karger.com/che
Mathias Wittau, MD

University of Ulm

Department of Visceral Surgery

Steinhövelstrasse 9, DE-89075 Ulm (Germany)

Tel.+49 7315005 3500, E-Mail mathias.wittau@uniklinik-ulm.de 
though several characteristics make their use attractive as a prophylactic antibiotic agent before elective colorectal surgery $[1,2]$. Carbapenems are $\beta$-lactam antibiotics with a broad spectrum of antimicrobial activity against Gram-positive and Gram-negative pathogens, including anaerobic species [3]. They are typically stable against hydrolysis by most chromosomal- and plasmid-mediated $\beta$-lactamases, including the extended-spectrum $\beta$-lactamases [2].

Ertapenem is a structurally distinct carbapenem. Due to the $1 \beta$-methyl group, it has an increased stability to renal dehydropeptidase-I, and therefore, must not be combined with cilastatin for protection against renal dehydropeptidase-I. Furthermore, the benzoate anionic side chain makes the compound highly protein bound which leads to an average half-life of $3.8 \mathrm{~h}$ [4]. The pharmacokinetics (PK) of ertapenem in healthy young adults support its use as a once-daily antibiotic at a dose of $1 \mathrm{~g}$ intravenously against susceptible isolates $[4,5]$. Ertapenem is active against a wide variety of organisms but has limited activity against Pseudomonas aeruginosa and no clinically relevant activity against Enterococcus faecium, Enterococcus faecalis and methicillin-resistant Staphylococcus aureus. Owing to its antimicrobial spectrum, ertapenem seems to be an efficacious drug for the treatment of intra-abdominal infections and for the prophylaxis of surgical site infections after colorectal surgery. However, approximately $84-96 \%$ of ertapenem is bound to plasma proteins in healthy volunteers, and this protein binding decreases as plasma concentrations of ertapenem increase [5]. Since only the unbound fraction of ertapenem can penetrate into the tissue, only $4-16 \%$ of the mean total plasma concentration is contributing to the antimicrobial activity [6]. To date, there are only limited data on tissue concentrations of ertapenem [6-9]. Data on tissue concentrations in intra-abdominal organs were reported by our group previously [6]. We determined penetration ratios and tissue concentrations in uninfected intra-abdominal organs, amongst others for colorectal tissue. Nevertheless, there are only limited data on tissue kinetics of ertapenem in colorectal tissue more than $3 \mathrm{~h}$ after administration of the drug. This is of special importance due to the fact that for carbapenem antibiotics, the time of the unbound drug concentration above the minimum inhibitory concentration required to inhibit the growth of $90 \%$ of organisms $\left(\mathrm{MIC}_{90}\right)$ for a bacteriostatic effect should be at least $20 \%$ of the dosing interval [10] to achieve bacteriostasis at $24 \mathrm{~h}$ in animal infection models. For ertapenem, a target of $25 \%$ was determined in a murine infection model [11].
Population PK modeling and Monte Carlo simulation (MCS) have become the methods of choice to predict the effectiveness of antibiotic dosage regimens in animal infection models and patients $[10,12-14]$. To analyze the data in the present study, we applied the latest 3-stage hierarchical population PK modeling methods and used prior data from the literature on the saturable protein binding of ertapenem $[5,15,16]$.

The purpose of this study was to determine the tissue kinetics of ertapenem in colorectal tissue starting $3 \mathrm{~h}$ up to $>6 \mathrm{~h}$ ( $25 \%$ of dosing interval) after administration of ertapenem. Population PK modeling and MCS were used to characterize the $\mathrm{PK} /$ pharmacodynamic $(\mathrm{PD})$ profile of ertapenem in plasma and colorectal tissue.

\section{Methods}

Study Design

This prospective, unicentric, open-label study was conducted at the Department of Visceral Surgery, University of Ulm, Ulm, Germany, from September 2007 to December 2009 (ClinicalTrials.gov identifier: NCT 00535652). The ethics committee of the University of Ulm and The Federal Institute for Drug and Medical Devices of Germany approved the protocol, and prior written informed consent was obtained from all study participants. The trial was conducted in accordance with the revised version of the Declaration of Helsinki and current revisions of the Good Clinical Practice Guidelines of the European Commission.

\section{Patients}

Hospitalized patients $\geq 18$ years old requiring surgical intervention (open or laparoscopic surgery) at the colon and/or rectum were eligible for this study.

Exclusion criteria were: pregnancy or lactation in women, emergency surgery, history of serious allergy or intolerance to $\beta$ lactam antibiotics, systemic antimicrobial therapy with ceftazidime (internal standard of high-performance liquid chromatography/mass spectrometry, HPLC/MS) within a 7-day period prior to study entry, ongoing intra-abdominal infections, terminal illness, chronic immunosuppressive therapy, severe diseases of the liver, e.g., cirrhosis of the liver with ALT or AST $>6 \times$ the upper limit of normal (ULN) and bilirubin $>3 \times$ ULN, severe renal insufficiency with a creatinine clearance $\leq 30 \mathrm{ml} / \mathrm{min}$, neutrophil count $<1,000$ cells $/ \mathrm{mm}^{3}$, platelets $<75,000$ cells $/ \mathrm{mm}^{3}$ and coagulation studies (international normalized ratio) $>1.5 \times$ ULN, as well as ongoing therapy with valproic acid.

\section{Study Medication and Administration}

All patients received $1 \mathrm{~g}$ of ertapenem (Invanz ${ }^{\odot}$, Merck \& Co., Inc., Whitehouse Station, N.J., USA) intravenously. To determine tissue concentrations from 3 to $6 \mathrm{~h}$ after administration of ertapenem, the dosing time was adjusted to the estimated duration of the planned surgical procedure. The dose was given as a $10-\mathrm{min}$ intravenous infusion between 60 and $180 \mathrm{~min}$ prior to surgical incision. Due to missing data of ertapenem tissue concentrations be- 
yond $3 \mathrm{~h}$ after dose administration, a standard antibiotic prophylaxis of $1.5 \mathrm{~g}$ cefuroxime $+0.5 \mathrm{~g}$ metronidazole was administered $30 \mathrm{~min}$ prior to surgical incision for perioperative prophylaxis.

\section{Collection of Tissue and Blood Samples}

Tissue samples were taken during surgery at different time points and immediately after resection from the specimen. Tissue samples were taken at the transection line of the colon/rectum from macroscopically normal parts of the colorectal tissue, i.e. not from malignant tissue. In order to avoid blood contamination, adherent blood was removed by rinsing the samples with sterile saline for a few seconds. After this, samples were immediately shock frozen in liquid nitrogen. Samples were stored after resection at $-80^{\circ} \mathrm{C}$ until analysis.

Blood samples were taken at the same time points as for tissue samples. Blood samples were immediately cooled at $4^{\circ} \mathrm{C}$. Plasma was obtained by centrifugation of blood samples at 4,000 rpm for $10 \mathrm{~min}$ at $4^{\circ} \mathrm{C}$; samples were split into two aliquots and immediately frozen and stored at $-80^{\circ} \mathrm{C}$ until analysis.

\section{Bioanalytical Methods}

Ertapenem concentrations in plasma and tissue samples were determined by HPLC/MS. For details, see Koal et al. [17]. Plasma samples were immediately stored at $-80^{\circ} \mathrm{C}$ and stabilized by addition of $100 \mathrm{mM}$ 2-(4-morpholino)ethylsulphonate (MES) buffer ( $\mathrm{pH}$ 6.5) $1 / 1$ (v/v) after thawing. Frozen tissue samples were ground in liquid nitrogen frozen mortar. Pulverized tissue $(200 \mathrm{mg})$ was treated immediately with $600 \mu \mathrm{l}$ of $100 \mathrm{mM}$ MES buffer (pH 6.5). The tissue/MES sample was homogenized 3 times for $10 \mathrm{~s}$ by using an Ultra-Turrax machine at $4^{\circ} \mathrm{C}$. To $100 \mu \mathrm{l}$ of plasma/MES or human tissue/MES samples, $400 \mu \mathrm{l}$ methanol including $12.5 \mu \mathrm{g} / \mathrm{ml}$ of the internal standard ceftazidime was added for protein precipitation in polypropylene tubes. Samples were immediately vortexed $(20 \mathrm{~s})$ and centrifuged for $10 \mathrm{~min}$ at $20,800 \mathrm{~g}$ at $4^{\circ} \mathrm{C}$. A volume of $400 \mu \mathrm{l}$ of the supernatant was transferred into a $1.5-\mathrm{ml}$ sample vial, concentrated to dryness using nitrogen gas stream at room temperature. Dried samples were dissolved with $150 \mu \mathrm{l} \mathrm{H}_{2} \mathrm{O}$ to achieve appropriate start conditions for HPLC separation. After centrifugation for $5 \mathrm{~min}$ at $20,800 \mathrm{~g}$ at $4^{\circ} \mathrm{C}, 100 \mu \mathrm{l}$ of the supernatant was transferred into a $1.5-\mathrm{ml}$ sample vial with $200-\mu l$ volume micro insert. During LC-MS analysis, samples were kept at $4{ }^{\circ} \mathrm{C}$.

LC-MS was performed by direct coupling from HPLC column (Synergi $4 \mu$ Polar-RP 80A Mercury; $10 \times 2.0 \mathrm{~mm}$ ) used in combination with the HPLC column SecurityGuard TM (Phenomenex, Aschaffenburg, Germany) to the MS system (LC-MSD, Agilent 1100, Waldbronn, Germany) equipped with electrospray ion source. At zero time, an aliquot 20 - $\mu$ l sample was injected and analyzed by the following analysis. Pump A supplied $500 \mu \mathrm{l} / \mathrm{min}$ start eluent (100\% eluent $\mathrm{A}=\mathrm{H}_{2} \mathrm{O}, 2 \mathrm{mM} \mathrm{NH}_{4} \mathrm{Oac}, 0.1 \%$ acetic acid, $\mathrm{pH}$ 3.8). HPLC separation was proceeded by using a linear HPLC gradient with a constant total flow rate of $500 \mu \mathrm{l} / \mathrm{min}$, which means gradient formation from $0.0 \mathrm{~min}$ (100\% eluent A, $0 \%$ eluent B $=100 \%$ methanol) to $5.0 \mathrm{~min}$ ( $10 \%$ eluent A, $90 \%$ eluent B). For system re-equilibration to next sample analysis, the total HPLC eluent was changed back to $100 \%$ eluent A at $5.1 \mathrm{~min}$ (500 $\mu \mathrm{l} / \mathrm{min})$. A total analysis time of $8 \mathrm{~min}$ was obtained. MS detection in negative selected ion monitoring (SIM) detection mode (capillary voltage $-4,000 \mathrm{~V}$, temperature $350^{\circ} \mathrm{C}$, gas supply 100 psi, nebulizer gas $35 \mathrm{psi}$, drying gas $10 \mathrm{l} / \mathrm{min}$ ) allows detection of ertapenem $\left(t_{R}=3.7 \mathrm{~min}\right.$, SIM $\left.473.9 \mathrm{amu}\right)$ and internal standard ceftazidime $\left(t_{R}=3.1 \mathrm{~min}\right.$, SIM $\left.465.8 \mathrm{amu}\right)$. Ertapenem (calibration curve $0.1-50.0 \mu \mathrm{g} / \mathrm{ml}$ ) was a kind gift from MSD (Whitehouse Station, N.J., USA) and ceftazidime used as internal standard was purchased from Sigma Aldrich (Steinheim, Germany).

Assay performance parameters for determination of ertapenem in plasma and tissue samples by LC-MS have been described earlier [17]. Extracted tissue samples containing the internal standard ceftazidime were quantified by using ertapenem calibrator samples in pooled human plasma also containing ceftazidime as internal standard. Koal et al. [17] showed the method validation results for accuracy and precision in plasma samples. Relative standard deviation values for intra- and inter-day precision determined at three concentrations are shown with excellent relative standard deviation $<10 \%$. The accuracy was assessed by means of laboratory in-house extra spiked plasma samples and yielded well-acceptable accuracies of $>90 \%$.

\section{Assessment of Protein Binding in Plasma}

For the investigation of ertapenem plasma protein binding, a rapid equilibration dialysis approach was applied [18]. Commercially available rapid equilibration dialysis devices (Pierce, Rockford, Ill., USA) were used according to the manufacturer's instruction. Briefly, 400- $\mu$ l plasma samples containing free and protein-bound ertapenem were added to the sample chamber, whereas the buffer chambers were filled with $600 \mu$ l of a $10-\mathrm{mM}$ MES buffer, pH 6.5. After incubation for $18 \mathrm{~h}$ at $37^{\circ} \mathrm{C}$ on an orbital shaker $(100 \mathrm{rpm})$, free ertapenem concentrations were directly determined using a $50-\mu l$ aliquot from the buffer chamber by the established LC-MS method $[6,17]$. Drug stability under these conditions was monitored in control samples.

Population PK Modeling

Modeling Dataset

The population PK model was developed using the total ertapenem concentrations in plasma and colorectal tissue from 38 patients in total. Data from a previous PK study [6] with ertapenem in plasma and colon tissue were simultaneously modeled with the data from the present study to obtain robust PK parameter estimates. Six patients contributed in a total of 15 observations for unbound ertapenem in plasma. The dataset comprised 121 observations for the total ertapenem concentration in plasma with a range of 1-7 observations per patient and 66 concentrations in colorectal tissue with 1-4 observations per patient.

\section{Structural Model}

Initially, the total ertapenem concentrations in plasma were described by models with one, two or three disposition compartments and first-order, mixed-order (Michaelis-Menten) or parallel first-order and mixed-order elimination. Subsequently, an additional compartment was included for the colon. The differential equations of the full model were:

$$
\frac{\mathrm{dA} 1}{\mathrm{dt}}=\mathrm{R}(1)-\left(\mathrm{CL}+\mathrm{CLic}+\mathrm{CLic}_{\text {colon }}\right) \cdot \mathrm{C} 1+\mathrm{CLic} \cdot \mathrm{C} 2+\mathrm{CLic}_{\text {colon }} \cdot \mathrm{C} 3
$$

$\frac{\mathrm{dA} 2}{\mathrm{dt}}=\mathrm{CLic} \cdot(\mathrm{C} 1-\mathrm{C} 2)$

$\frac{\mathrm{dA} 3}{\mathrm{dt}}=\mathrm{CLic}_{\text {colon }} \cdot(\mathrm{C} 1-\mathrm{C} 3)$ 
Table 1. Population PK parameter estimates for ertapenem in the plasma and colon

\begin{tabular}{|c|c|c|c|}
\hline Parameter & Symbol & Population mean & BSV \\
\hline \multicolumn{4}{|l|}{ Disposition parameters } \\
\hline Total clearance, $1 / \mathrm{h}$ & CL & $12.5(27)^{1}$ & $0.182^{2}(31)^{3}$ \\
\hline Intercompartmental clearance to the first peripheral compartment, $1 / \mathrm{h}$ & CLic & $16.5(10)^{1}$ & $0.053(46)$ \\
\hline Intercompartmental clearance to the colon compartment, $1 / \mathrm{h}$ & CLic $_{\text {colon }}$ & $0.605(15)^{1}$ & 0.15 (fixed) \\
\hline Volume of distribution of the central compartment, liters & V1 & $24.3(29)^{1}$ & $0.216(66)$ \\
\hline Volume of distribution of the first peripheral compartment, liters & $\mathrm{V} 2$ & $15.7(16)^{1}$ & $0.629(33)$ \\
\hline Volume of distribution of the colon compartment, liters & $\mathrm{V} 3$ & $0.231(23)^{1}$ & 0.15 (fixed) \\
\hline $\begin{array}{l}\text { AUC in the colon divided by area under the unbound } \\
\text { concentration time curve in plasma }\end{array}$ & $\mathrm{F}_{\text {colon }}$ & $0.856(26)$ & $0.305(29)$ \\
\hline \multicolumn{4}{|l|}{ Parameters for binding in plasma } \\
\hline Linear binding component & $\mathrm{B}_{\text {lin }}$ & $1.39(36)$ & $0.287(33)$ \\
\hline Dissociation constant for saturable binding & $\mathrm{Kd}$ & $32.0(34)$ & $0.301(62)$ \\
\hline Ratio of maximum binding capacity and Kd & $\mathrm{B}_{\text {sat }} / \mathrm{Kd}$ & $4.73(58)$ & $0.392(132)$ \\
\hline \multicolumn{4}{|l|}{ Standard deviations of residual error terms } \\
\hline Additive residual error for total plasma concentrations, $\mathrm{mg} / \mathrm{l}$ & & $0.221(7.0)$ & \\
\hline Proportional residual error for total plasma concentrations & & $0.0901(7.2)$ & \\
\hline Additive residual error for concentrations in colon tissue, $\mathrm{mg} / \mathrm{l}$ & & $0.954(19)$ & \\
\hline Proportional residual error for concentrations in colon tissue & & $0.00149(448)$ & \\
\hline Additive residual error for unbound plasma concentrations, $\mathrm{mg} / \mathrm{l}$ & & $0.472(16)$ & \\
\hline Proportional residual error for unbound plasma concentrations & & $0.181(17)$ & \\
\hline
\end{tabular}

Figures in parentheses are the relative standard error given as percentages.

1 All clearance and volume of distribution parameters refer to unbound ertapenem.

2 The BSV estimates represent the apparent coefficient of variation of a normal distribution on the natural logarithmic scale.

3 The relative standard errors of the BSV estimates refer to the variance on the natural logarithmic scale.

Initial conditions were zero for all compartments. All amounts refer to unbound ertapenem. A1 represents the amount of ertapenem in the central compartment, A2 the amount in the first peripheral compartment, and A3 the amount in the colon compartment. $\mathrm{C} 1, \mathrm{C} 2$ and $\mathrm{C} 3$ are the unbound concentrations in the respective compartment and are obtained by dividing the amount of drug by the volume of the respective compartment. $\mathrm{R}(1)$ is a zero-order time-delimited infusion rate. All clearance and volume of distribution parameters refer to unbound ertapenem (as defined in table 1). A density of $1 \mathrm{~g} / \mathrm{ml}$ was assumed for the modeling of colon tissue concentrations.

Models were compared by the objective function $(-1 \cdot \log$-likelihood) in S-ADAPT, standard diagnostic plots, the plausibility of parameter estimates, and normalized prediction distribution error plots [19]. To assure that the simulated concentration time profiles adequately captured the central tendency and betweensubject variability (BSV) of the observations, visual predictive checks were applied as described previously [20].

\section{Parameter Variability Model and Covariate Effects}

All PK parameters were described by an exponential BSV model using a major diagonal variance-covariance matrix. As the present study had relatively sparse data from 38 patients, standard allometric theory $[21,22]$ was applied. All clearances were scaled with an allometric exponent of 0.75 (not estimated) and all volumes of distribution with an exponent of 1.0, as described previously [20].

\section{Observational Model and Protein Binding}

A combined additive plus proportional residual error model was used for the total ertapenem concentrations in plasma and colon tissue and for the unbound ertapenem concentrations in plasma.

Wong et al. [16] reported dissociation constants (Kd) for rat and monkey of 5.25 and $4.13 \mathrm{mg} / \mathrm{l}$ for the high-affinity binding site and of 2,191 and 3,471 mg/l for the low-affinity binding site of ertapenem in plasma. As the highest concentration in the present study was approximately 10 -fold lower than the $\mathrm{Kd}$ of the low-affinity binding site, a model with linear binding for the lowaffinity binding site and saturable binding for the high-affinity binding site was employed. Protein binding was assumed to be instantaneous. The total ertapenem concentration in plasma $\left(\mathrm{C}_{\mathrm{tot} \text {, plasma }}\right)$ was described based on the unbound ertapenem concentration in plasma $(\mathrm{C} 1)$ using a linear $\left(\mathrm{B}_{\text {lin }}\right)$ and a saturable binding component with a maximum binding capacity $\left(\mathrm{B}_{\mathrm{sat}}\right)$ :

$\mathrm{C}_{\text {tot, plasma }}=\mathrm{C} 1 \cdot\left(1+\mathrm{B}_{\text {lin }}+\frac{\mathrm{B}_{\text {sat }}}{\mathrm{Kd}+\mathrm{C} 1}\right)$ 
Table 2. Mean total tissue concentration of ertapenem in colorectal tissue following a single 1-gram dose intravenously

\begin{tabular}{lll}
\hline $\begin{array}{l}\text { Time after } \\
\text { administration, min }\end{array}$ & Samples & $\begin{array}{l}\text { Mean } \pm \text { SD ETP tissue } \\
\text { concentration, mg/kg }\end{array}$ \\
\hline $135-164$ & 4 & $5.9 \pm 3.0$ \\
$165-194$ & 5 & $6.4 \pm 2.3$ \\
$195-224$ & 5 & $5.7 \pm 1.7$ \\
$225-254$ & 6 & $5.5 \pm 2.4$ \\
$255-284$ & 3 & $4.3 \pm 0.6$ \\
$285-314$ & 7 & $3.3 \pm 0.7$ \\
$315-344$ & 4 & $2.6 \pm 0.29$ \\
$345-374$ & 3 & $3.5 \pm 0.6$ \\
$375-404$ & 2 & $3.3 \pm 0.9$ \\
$405-434$ & 2 & $2.8 \pm 0.8$ \\
$435-464$ & 2 & $2.3 \pm 0.8$ \\
$465-494$ & 2 & $3.1 \pm 1.6$ \\
$495-524$ & 1 & 4.5 \\
\hline
\end{tabular}

$\mathrm{ETP}=$ Ertapenem humans and rat, a large uncertainty with 200\% relative standard error was used for each of these population means and BSV terms of the three binding parameters. All other model parameters were estimated without prior information.

\section{Monte Carlo Simulations}

MCS and visual predictive checks were performed in NONMEM VI (release 6.2; NONMEM Project Group, University of California, San Francisco, Calif., USA) [27], as described previously [20]. Unbound drug concentrations in plasma and colorectal tissue were simulated without residual error based on the final model for 11,400 virtual patients. The PK profiles and target attainment probabilities were calculated for the first $24 \mathrm{~h}$ of therapy for either $1,000 \mathrm{mg}$ ertapenem dosed at $0 \mathrm{~h}$ or for $500 \mathrm{mg}$ each dosed at 0 and $12 \mathrm{~h}$. The probability of attaining a free time above $\operatorname{MIC}\left(f \mathrm{~T}_{>\mathrm{MIC}}\right)$ of at least $20 \%$ was used as bacteriostasis target, and a $f \mathrm{~T}_{>\mathrm{MIC}}$ of at least $40 \%$ was used as target for near-maximal bacterial killing by carbapenems $[10,14,28]$. The modeled unbound drug concentration in plasma and the ertapenem concentration in colorectal tissue were used to calculate the probability of target attainment.

\section{Results}

Twenty-three patients, 4 females and 19 males, with a

It was assumed that only unbound ertapenem can equilibrate between the central and the colon compartment. To account for differences in the unbound area under the curve (AUC) in the colon and central compartment, a factor $\left(\mathrm{F}_{\text {colon }}\right)$ was included to describe the observed colon concentration $\left(\mathrm{C}_{\text {colon, obs }}\right)$ :

$$
\mathrm{C}_{\text {colon, obs }}=\mathrm{F}_{\text {colon }} \cdot \mathrm{C} 3
$$

$\mathrm{F}_{\text {colon }}$ describes the AUC in the colon compartment divided by the unbound AUC in the central compartment. To estimate the average extent of protein binding at the concentration range in this study, a model without the saturable binding component was additionally explored (i.e. with the saturable binding component fixed to zero).

\section{Computation}

Nonlinear mixed-effects modeling was performed using the importance sampling Monte Carlo Parametric Expectation Maximization algorithm (MC-PEM; pmethod =4) in S-ADAPT (version 1.57) on a parallelized computer cluster. The SADAPTTRAN pre- and post-processor tool was used to facilitate model building and evaluation [23, 24]. All model parameters were simultaneously estimated based on all ertapenem concentrations.

As there were only 15 observations for the unbound ertapenem in plasma, we used prior information on protein binding during population PK modeling. A three-stage hierarchical population approach was used in S-ADAPT via the $h_{\text {prior }}=1$ option, as described previously $[25,26]$. Based on the binding data in rat reported by Wong et al. [16], the linear binding component had a prior mean of 1.85 , a Kd of $5.24 \mathrm{mg} / \mathrm{l}$ and a ratio of the saturable binding component/Kd of 26.2. These three model parameters were assumed to have a BSV of $30 \%$ (coefficient of variation). To account for the potential differences between protein binding in median age of 55 years (range 25-76) were enrolled in the study. Three patients did not receive study medication and were therefore excluded from the analysis. Median weight was $78 \mathrm{~kg}$ (range 57-125), median body mass index was 26.3 (range 19.7-34.8).

After administration of ertapenem, no suspected unexpected serious adverse reactions were observed. The underlying diseases of the patients were colon carcinoma $(n=10)$, colonic diverticulosis $(n=3)$, carcinoma of the rectum $(\mathrm{n}=9)$ and rectal polyp $(\mathrm{n}=1)$.

\section{Tissue Concentration}

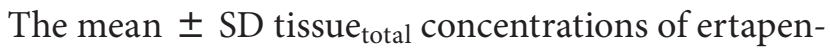
em in the colorectal tissue (30-min clusters) are listed in table 2 and shown in figure 1. The highest ertapenem concentration in this trial was $6.4 \pm 2.3 \mathrm{mg} / \mathrm{kg}$ at $165-$ $194 \mathrm{~min}$, followed by a decrease to a minimum of $2.3 \pm$ $0.80 \mathrm{mg} / \mathrm{kg}$ at $435-464 \mathrm{~min}$.

\section{Total Ertapenem Plasma Concentration}

The mean \pm SD total plasma concentrations of ertapenem (30-min clusters) are listed in table 3 and shown in figure 2 . The highest total plasma concentration in this trial was $51.34 \pm 9.4 \mathrm{mg} / \mathrm{l}$ at $165-194 \mathrm{~min}$, followed by a decrease to a minimum of $13.5 \pm 4.2 \mathrm{mg} / \mathrm{kg}$ at $405-434$ $\min$. 
Fig. 1. Total tissue concentration of ertapenem in colorectal tissue following a single 1-gram dose intravenously.
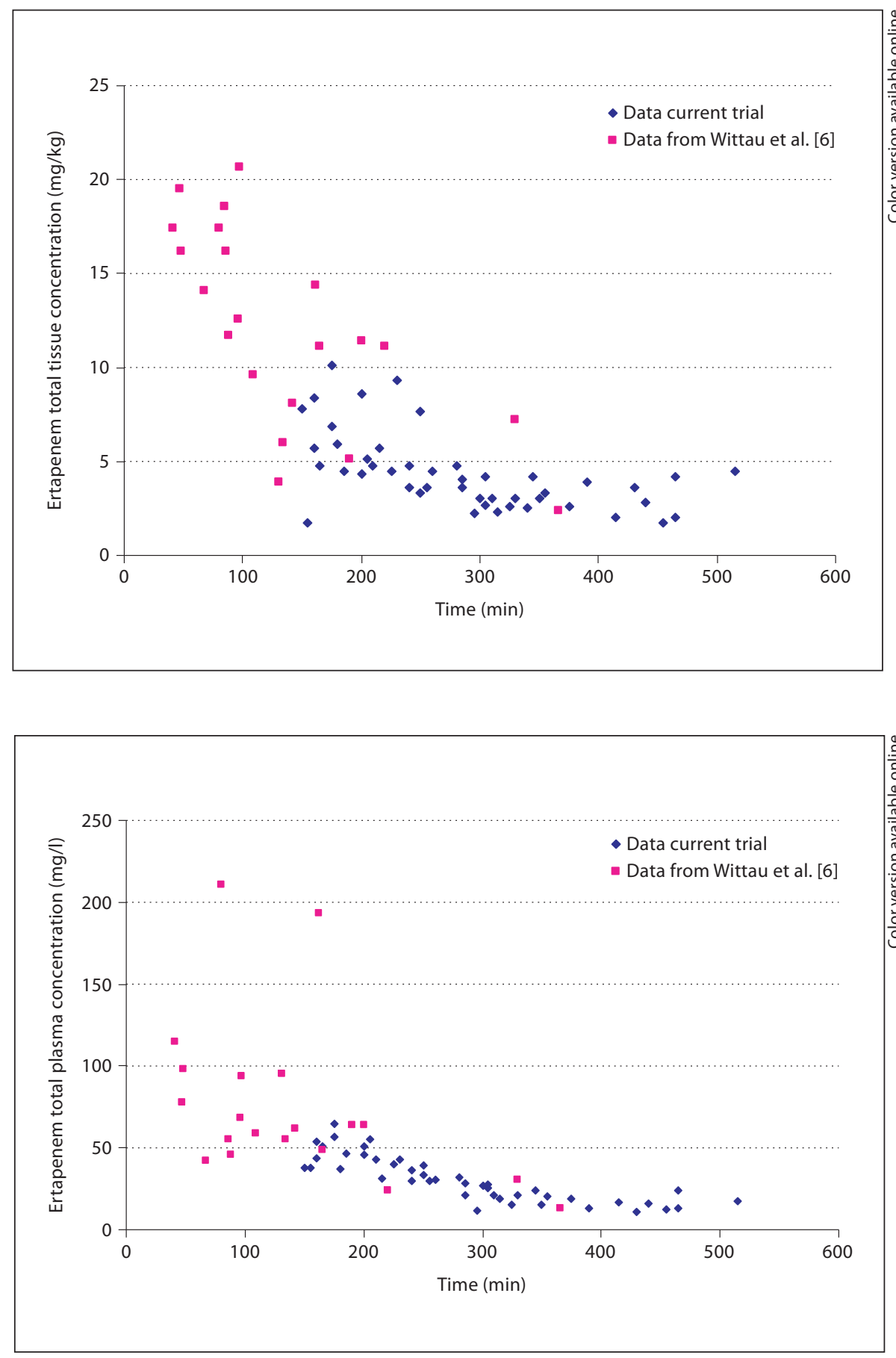

Fig. 2. Total plasma concentration of ertapenem following a single 1-gram dose intravenously. Data of plasma concentration kinetics from Wittau et al. [6] are not shown.

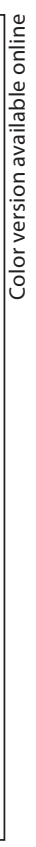

\section{Tissue to Plasma Ratio}

The mean \pm SD tissue total $_{\text {plasmat }}$ total ratios of ertapenem (30-min clusters) are listed in table 4 . The tissue total $/$ plasma $_{\text {total }}$ ratios were stable over the time with a mean of $0.168 \pm 0.04$ (range 0.124-0.26).

\section{Unbound Ertapenem Plasma Concentration}

In 6 patients, unbound ertapenem concentrations in plasma were available. The mean \pm SD unbound plasma concentrations of ertapenem (30-min clusters) are listed in table 5. The highest unbound plasma concentration in this trial was $7.05 \pm 1.1 \mathrm{mg} / \mathrm{l}$ at $165-194 \mathrm{~min}$, followed by 
Table 3. Mean total plasma concentration of ertapenem following a single 1-gram dose intravenously

\begin{tabular}{lll}
\hline $\begin{array}{l}\text { Time after } \\
\text { administration, min }\end{array}$ & Samples & $\begin{array}{l}\text { Mean } \pm \text { SD ETP total } \\
\text { plasma concentration, mg/l }\end{array}$ \\
\hline $135-164$ & 4 & $43.43 \pm 7.5$ \\
$165-194$ & 5 & $51.34 \pm 9.4$ \\
$195-224$ & 5 & $45.15 \pm 9.1$ \\
$225-254$ & 6 & $36.96 \pm 4.8$ \\
$255-284$ & 3 & $30.88 \pm 0.9$ \\
$285-314$ & 7 & $23.08 \pm 5.9$ \\
$315-344$ & 3 & $18.4 \pm 3.1$ \\
$345-374$ & 3 & $19.83 \pm 4.3$ \\
$375-404$ & 2 & $16.05 \pm 4.3$ \\
$405-434$ & 2 & $13.50 \pm 4.2$ \\
$435-464$ & 2 & $14.30 \pm 2.6$ \\
$465-494$ & 2 & $18.65 \pm 7.5$ \\
$495-524$ & 1 & 17.20 \\
\end{tabular}

$\mathrm{ETP}=$ Ertapenem
Table 4. Mean $\pm \mathrm{SD}$ tissue $_{\text {total }} /$ plasma $_{\text {total }}$ ratios of ertapenem (30min clusters)

\begin{tabular}{ll}
\hline $\begin{array}{l}\text { Time after } \\
\text { administration, min }\end{array}$ & Mean \pm SD tissue total $_{\text {plasma }}$ total ratios \\
\hline $135-164$ & $0.136 \pm 0.07$ \\
$165-194$ & $0.124 \pm 0.03$ \\
$195-224$ & $0.128 \pm 0.03$ \\
$225-254$ & $0.145 \pm 0.05$ \\
$255-284$ & $0.138 \pm 0.41$ \\
$285-314$ & $0.147 \pm 0.04$ \\
$315-344$ & $0.168 \pm 0.05$ \\
$345-374$ & $0.178 \pm 0.02$ \\
$375-404$ & $0.218 \pm 0.11$ \\
$405-434$ & $0.23 \pm 0.15$ \\
$435-464$ & $0.154 \pm 0.15$ \\
$465-494$ & $0.162 \pm 0.017$ \\
$495-524$ & 0.26
\end{tabular}

Table 5. Mean total and free plasma concentration of ertapenem following a single 1-gram dose intravenously and fraction free plasma concentration

\begin{tabular}{|c|c|c|c|c|c|c|}
\hline $\begin{array}{l}\text { Time after } \\
\text { administration } \\
\text { min }\end{array}$ & Samples & $\begin{array}{l}\text { Mean } \pm \text { SD ETP total } \\
\text { plasma concentration } \\
\mathrm{mg} / \mathrm{l}\end{array}$ & $\begin{array}{l}\text { Mean } \pm \text { SD ETP free } \\
\text { plasma concentration } \\
\text { mg/l }\end{array}$ & $\begin{array}{l}\text { Fraction free } \\
\text { plasma } \\
\text { concentration } \\
\%\end{array}$ & $\begin{array}{l}\text { Mean } \pm \text { SD ETP total } \\
\text { tissue concentration } \\
\mathrm{mg} / \mathrm{kg}\end{array}$ & $\begin{array}{l}\text { Ratio } \\
\text { tissue }_{\text {total }} / \\
\text { plasma free }_{\text {free }}\end{array}$ \\
\hline 165-194 & 6 & $45.91 \pm 12.2$ & $7.05 \pm 1.1$ & 15.3 & $6.27 \pm 0.9$ & $0.89 \pm 0.23$ \\
\hline $195-224$ & 3 & $42.68 \pm 10.2$ & $6.9 \pm 0.9$ & 16.2 & $6.4 \pm 2.4$ & $0.91 \pm 0.31$ \\
\hline $225-254$ & 1 & 38.85 & 5.5 & 14.3 & 7.65 & 1.3 \\
\hline $255-284$ & 3 & $27.95 \pm 4.7$ & $4.4 \pm 0.8$ & 15.7 & $4.4 \pm 0.37$ & $1.02 \pm 0.15$ \\
\hline $315-344$ & 1 & 20.9 & 3.1 & 14.8 & 3.0 & 0.96 \\
\hline $495-524$ & 1 & 17.20 & 3.25 & 18.9 & 4.5 & 1.38 \\
\hline
\end{tabular}

$\mathrm{ETP}=$ Ertapenem

a decrease to a minimum of $3.1 \mathrm{mg} / \mathrm{l}$ at $315-344 \mathrm{~min}$. The fraction ertapenem plasma ${ }_{\text {free }}$ was on average $15.8 \pm$ $1.6 \%$ (range 14.3-18.9).

\section{Pooled Data}

Due to a similar patient cohort, identical tissue/blood sampling and bioanalytical methods, we were able to pool the data of this survey with the data from colorectal tissue of a previous trial [6]. Overall, the data of 38 patients were available.

Pharmacokinetics of Ertapenem in Colorectal Tissue

\section{Tissue Concentration}

The tissue concentrations of ertapenem in the colorectal tissue are also displayed in figure 1 . The highest ertapenem concentration was $17.7 \pm 1.6 \mathrm{mg} / \mathrm{kg}$ at $30-59 \mathrm{~min}$, followed by a decrease to a minimum of $2.72 \pm 0.8 \mathrm{mg} /$ $\mathrm{kg}$ at $360-419 \mathrm{~min}$.

\section{Total Ertapenem Plasma Concentration}

The total plasma concentrations are also displayed in figure 2. The highest total plasma concentration was 97 
Fig. 3. Visual predictive check showing the range of predicted and observed concentrations in plasma. a, b Total concentrations on semi-logarithmic (a) or linear scale (b). c Unbound concentrations. d Concentrations in colon tissue. Ideally, the median should capture the central tendency of the observations, and $10 \%$ of the observations should fall outside of each side of the $80 \%$ prediction interval (10$90 \%$ percentile).

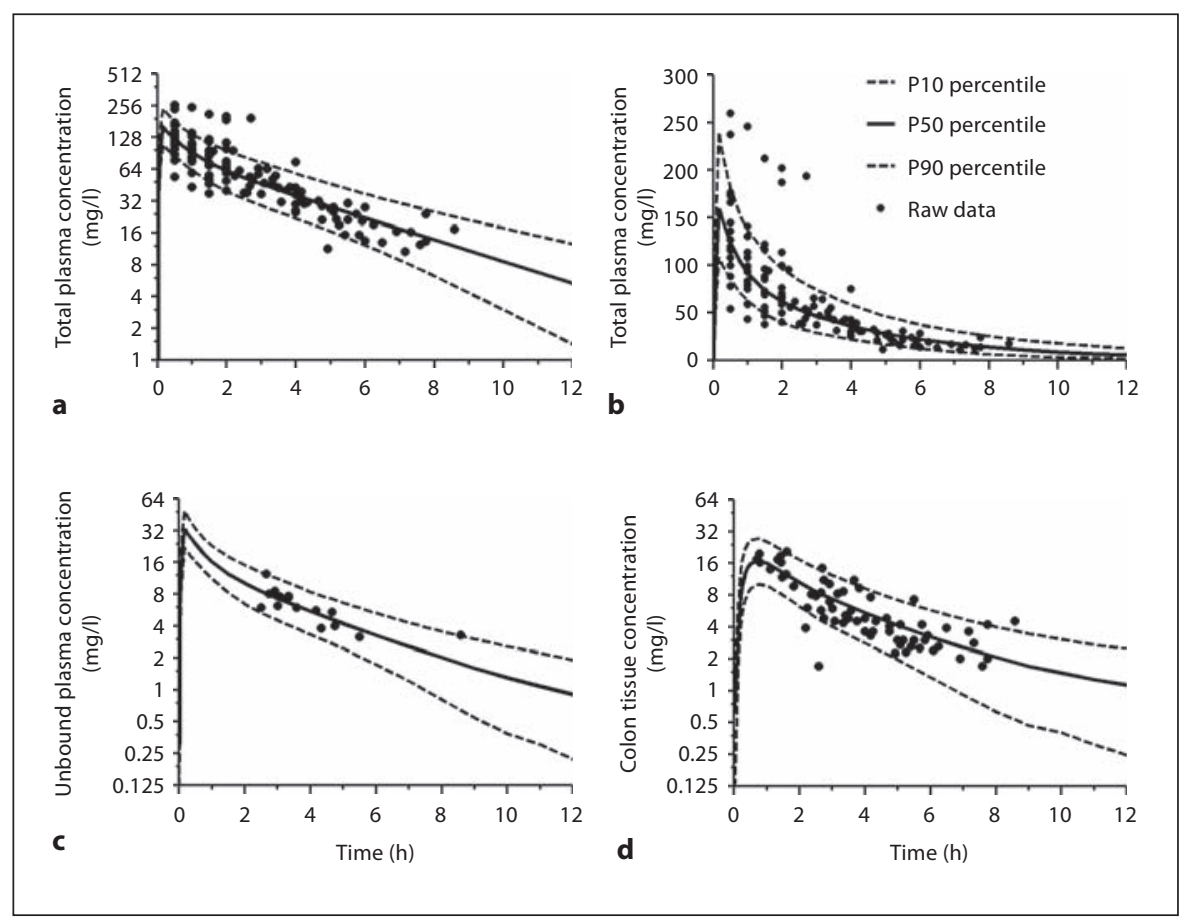

$\pm 18.5 \mathrm{mg} / \mathrm{l}$ at $30-59 \mathrm{~min}$, followed by a decrease to a minimum of $15.4 \pm 2.8 \mathrm{mg} / \mathrm{kg}$ at $360-419 \mathrm{~min}$.

\section{Tissue to Plasma Ratio}

The tissue total $/$ plasma $_{\text {total }}$ ratios of ertapenem were stable over the time, with a mean of $0.159 \pm 0.06$ (range $0.124-0.24)$.

\section{Population PK Modeling}

A model with two disposition compartments had a 12.2-point better ( $p=0.001$, likelihood ratio test) objective function compared to a model with one disposition compartment. Inclusion of a third compartment or of a saturable elimination process did not improve the objective function.

Total clearance of unbound ertapenem was estimated as $12.5 \mathrm{l} / \mathrm{h}$, with a coefficient of variation for BSV of $18.2 \%$ (table 1). The volume of distribution at steady state for unbound ertapenem (i.e. the sum of V1, V2 and V3) was approximately 40 liters. The population means of all but one disposition parameter were estimated reasonably precisely with relative standard errors $<40 \%$ (table 1).

The rate of equilibration between the colon and the central compartment was rapid (half-life of $15.9 \mathrm{~min}$ ). The AUC in the colon divided by the unbound AUC for unbound plasma concentrations was 0.856 (between-patient variability $31 \%$, range of individual estimates 0.39 1.60). The apparent volume of distribution of the colon compartment was small ( 0.231 liters), and therefore, this compartment had a negligible impact on the overall disposition of ertapenem, as expected.

Inclusion of a saturable binding component improved the objective function significantly ( $p<0.001$, likelihood ratio test). The estimated protein binding for total ertapenem concentrations in plasma between 0.1 and $300 \mathrm{mg} / 1$ was well comparable for models with or without use of prior information and for models with or without inclusion of the 15 observed unbound ertapenem concentrations. For the final model, the unbound fraction in plasma was $14-15 \%$ for total ertapenem concentrations below approximately $22 \mathrm{mg} / \mathrm{l}, 19 \%$ at $100 \mathrm{mg} / \mathrm{l}$ and $25 \%$ at 250 $\mathrm{mg} / \mathrm{l}$.

Observed versus individual and observed versus population-fitted plots were precise and showed no obvious bias. No apparent bias was observed for the normalized prediction distribution error plots for all three dependent variables. The visual predictive check revealed an excellent predictive performance of the final model for total and unbound concentrations in plasma and for the colon concentrations (fig. 3). One patient with normal renal function had total plasma concentrations between 200 
Fig. 4. Probability of attaining the $\mathrm{PK} / \mathrm{PD}$ targets for bacteriostasis $\left(20 \% f \mathrm{~T}_{>\mathrm{MIC}}\right)$ and near-maximal bacterial killing (40\% $f \mathrm{~T}_{>\mathrm{MIC}}$ ) for the unbound plasma concentration and for the concentration in colon tissue. a Simulation of $1,000 \mathrm{mg}$ at $0 \mathrm{~h}$. b Simulation of $500 \mathrm{mg}$ each at 0 and $12 \mathrm{~h}$.

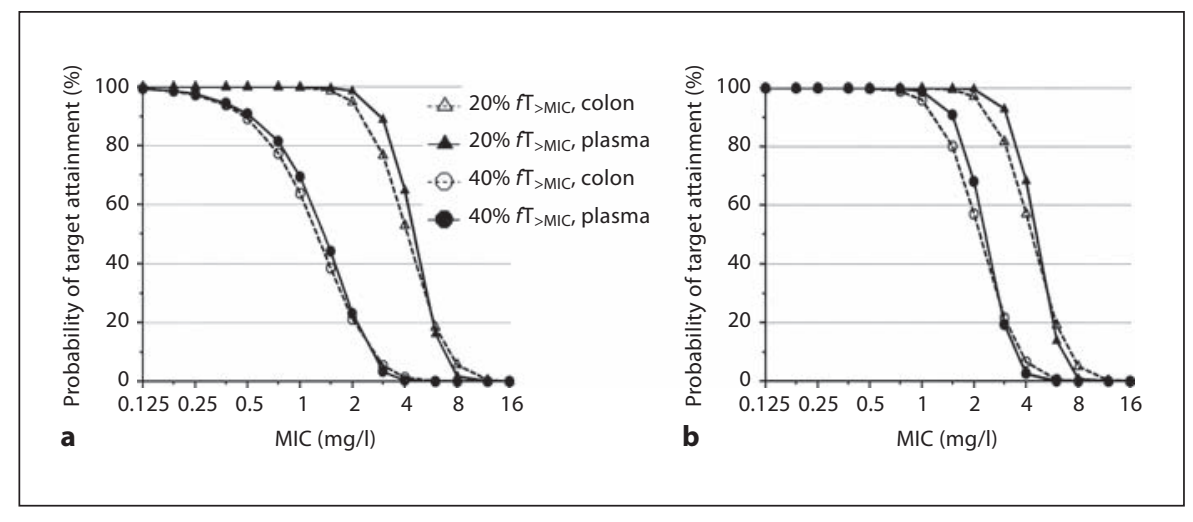

and $250 \mathrm{mg} / \mathrm{l}$ during the first $2 \mathrm{~h}$ which were notably higher compared to those of the other patients.

In the MCS (fig. 4), a single dose of 1,000 mg ertapenem achieved robust $(\geq 90 \%$ ) probabilities of target attainment up to an MIC of approximately $2 \mathrm{mg} / \mathrm{l}$ for the bacteriostasis target $\left(20 \% f \mathrm{~T}_{>\mathrm{MIC}}\right)$ and up to $0.25-0.5 \mathrm{mg} / \mathrm{l}$ for the near-maximal killing target $\left(40 \% f \mathrm{~T}_{>\mathrm{MIC}}\right)$. A dose of $500 \mathrm{mg}$ ertapenem at 0 and $12 \mathrm{~h}$ yielded robust probabilities of target attainment up to MICs of approximately $2 \mathrm{mg} / \mathrm{l}$ for the bacteriostasis target and up to $1-1.5 \mathrm{mg} / \mathrm{l}$ for the near-maximal killing target.

\section{Discussion}

Ertapenem exhibits concentration-dependent plasma protein binding, ranging from $96 \%$ at total plasma concentrations of $10 \mathrm{mg} / \mathrm{l}$ to $84 \%$ at total plasma concentrations of $300 \mathrm{mg} / \mathrm{l}$ [11]. Thus, only $4-16 \%$ of the total plasma concentration can penetrate into extravascular space and is responsible for antimicrobial activity. To cause bacterial killing, the tissue concentration of ertapenem should exceed $\mathrm{MIC}_{90}$ of most microorganisms found at the site of bacterial infection. To date, only one trial focused on ertapenem concentrations in colorectal tissue [6]. In that trial, tissue concentration of ertapenem in colorectal tissue up to $3 \mathrm{~h}$ after administration of $1 \mathrm{~g}$ was determined, and no data in colorectal tissue are available for after $3 \mathrm{~h}$ post-dose administration. For carbapenems, the $\mathrm{PK} / \mathrm{PD}$ target is $20 \% f \mathrm{~T}_{>\mathrm{MIC}}$ for bacteriostasis and $40 \% f \mathrm{~T}_{>\mathrm{MIC}}$ for near-maximal bacterial killing in an animal infection model at $24 \mathrm{~h}$. For a 24 -hour dosing interval for ertapenem, these targets correspond to 4.8 and $9.6 \mathrm{~h} \mathrm{[10].} \mathrm{In} \mathrm{agreement} \mathrm{with} \mathrm{these} \mathrm{common-}$ ly applied targets for carbapenems, a PK/PD of at least
$25 \%$ for ertapenem is required for bacteriostasis in a murine model [11].

We present the first data about ertapenem tissue concentration in colorectal tissue up to $8.5 \mathrm{~h}$ after administration with corresponding plasma total $_{\text {of all patients and }}$ plasma $_{\text {free }}$ concentration in 6 patients. The tissue total $_{\text {con- }}$ centration ranged from a maximum of $6.4 \mathrm{mg} / \mathrm{kg}$ at about $3 \mathrm{~h}$ to a minimum of $2.3 \mathrm{mg} / \mathrm{kg}$ at about $7.5 \mathrm{~h}$ (31\% of dosing interval); however, only a few samples were available after $6 \mathrm{~h}$ post-dose administration. The concentrations of ertapenem in colorectal tissue divided by the plasma concentration was $16-17 \%$ and showed no apparent trend over time after the rapid initial equilibration phase. Interestingly, with pooled data of two trials, the typical plasma elimination half-life was approximately $2.5 \mathrm{~h}$ (geometric mean) and somewhat lower as previously described in a pharmacokinetic trial with 6 included patients $(3.9 \mathrm{~h})$ [29].

The observed fraction plasma free in our patients of $15.8 \%$ is well comparable to earlier reports with healthy volunteers $[5,11]$ but differs notably from a recent trial with 6 patients (41-47\%) [29]. While the reasons for this difference are unclear, an ongoing systemic inflammatory response syndrome in patients of that trial compared to our 'relatively healthy' patient cohort may have contributed to this observation.

Further, this study presents the first population PK model for ertapenem which simultaneously modeled total and unbound ertapenem concentrations. Additionally, this study modeled the rate and extent of penetration into colorectal tissue. Penetration was rapid with an equilibration half-life of $16 \mathrm{~min}$ between colon and plasma. The area under the concentration-time curve in colorectal tissue divided by the area under the unbound plasma concentration-time curve was 0.856 . This ratio had notable between-patient variability, with ratios for 
individual patients ranging from 0.39 to 1.60 . These estimates are in agreement with the concept that binding of ertapenem in colorectal tissue was negligible and that the unbound AUC in plasma was similar to the AUC in colorectal tissue. Thus, we assumed that the concentrations in colorectal tissue represent unbound concentrations for the MCS. The population PK model developed in this study had excellent predictive performance for both total and unbound drug concentrations (fig. 4) which qualified this model for its use in MCS.

The MCS predicted robust probabilities of target attainment up to MICs of approximately $2 \mathrm{mg} / \mathrm{l}$ (fig. 4) for the bacteriostasis target and up to MICs of $0.25-0.5 \mathrm{mg} / \mathrm{l}$ for the near-maximal killing target for 1,000 mg ertapenem dosed at $0 \mathrm{~h}$. Probabilities of target attainment were similar for unbound plasma and for colorectal tissue concentrations. These MICs were approximately 2- to 4 -fold higher than the MICs with robust $(\geq 90 \%)$ target attainment probabilities reported by Chen et al. [14] for healthy volunteers, probably because our patients were older and had an age-related lower renal function. The probabilities of target attainment reported by Burkhardt et al. [30] are between the predictions from Chen et al. [14] and those from the present study. Administering 500 $\mathrm{mg}$ ertapenem at 0 and $12 \mathrm{~h}$ notably increased the probabilities of target attainment for the near-maximal killing target (fig. 4) and may therefore be an option for the treatment of patients with a suspected higher risk for infection or other clinical complications. Importantly, the PK/PD target values applied in this MCS refer to treatment of infections $[10,14,28]$ and not to prophylaxis, since we are not aware of PK/PD targets for $\beta$-lactams and prophylaxis.

Our estimated clearances and volumes of distribution (table 1) are based on unbound ertapenem concentrations and are therefore larger than the clearance and volume of distribution estimates based on total ertapenem reported for other studies. Based on a model with linear protein binding but without saturable binding, the time-averaged unbound fraction of ertapenem over the concentration range in our study was approximately $18.1 \%$. Consequently, the unbound clearances and volumes can be divided by approximately 5.53 to make our estimates roughly comparable to the estimates from literature studies based on total ertapenem concentrations. However, this conversion is only an approximation due to the saturable protein-binding component. This yields a typical clearance of approximately $2.3 \mathrm{l} / \mathrm{h}(38 \mathrm{ml} / \mathrm{min})$ and a volume of distribution at steady state of 7.3 liters for our study based on total ertapenem concentrations. These es- timates were well within the range of estimates from studies in healthy volunteers $[5,9,14,31]$ and (critically ill) patients $[15,32-34]$. Clearances and volumes of distribution at steady state for total ertapenem tend to be higher in patients compared to healthy volunteers and this effect is most pronounced in patients with hypoalbuminemia. This suggests that differences in protein binding between patients and healthy volunteers are the most likely reason for these differences in clearances and volumes of distribution.

The latest three-stage hierarchical population methodology was employed for the present study to simultaneously model total and unbound concentrations and to include prior information for estimation of the proteinbinding parameters. This methodology enabled us to develop a comprehensive PK model based on relatively sparse data from 38 patients. Prior information for binding parameters were obtained from Wong et al. [16], and a large uncertainty (200\% relative standard error) was used to obtain vague prior distributions in order to account for potential differences in protein binding between rat and patients.

The estimated unbound fraction in our study was $14-$ $15 \%$ for total ertapenem concentrations $<22 \mathrm{mg} / \mathrm{l}$ and $25 \%$ at $250 \mathrm{mg} / \mathrm{l}$ total ertapenem. Our patients had albumin and total serum protein concentrations at the lower end or (slightly) below the normal range. Albumin concentrations had a median of $37 \mathrm{~g} / \mathrm{l}$ (range 24-44) and total protein concentrations of $73 \mathrm{~g} / \mathrm{l}$ (range 42-83) in our study. These rather low albumin concentrations are a likely reason why the unbound fractions in the present study were higher compared to estimates reported for healthy volunteers [5]. Our unbound fractions were within the range of values reported for critically ill patients $[34,35]$ and healthy volunteers $[5,9,14,31]$.

Parameter estimates for protein binding in the present study were robust and not affected by inclusion of prior information or by inclusion of the 15 observed unbound ertapenem concentrations. A saturable proteinbinding component also improved the population fits before unbound ertapenem concentrations were included in the model. These data highly suggest that measurement of unbound ertapenem concentrations is important to optimize ertapenem therapy and that modeling of the saturable protein binding $[15,16,35]$ is greatly beneficial, if total ertapenem concentrations are measured.

In conclusion, our data indicate an adequate penetration of ertapenem into uninfected colorectal tissue up to $8.5 \mathrm{~h}$ ( $35 \%$ of dosing interval). In accordance with clini- 
cal studies [36-38], these pharmacokinetic results support the assumption that ertapenem is suitable for the treatment of colorectal infectious diseases, e.g., colonic diverticulitis. Further, these results contribute to a tailored chemotherapy of colorectal infections, which is of special importance, particularly in view of the increasing emergence of multidrug-resistant organisms [39, 40].

\section{Acknowledgments}

This study was supported by the University of Ulm, Department of Visceral Surgery, and in parts by a grant from MSD Sharp \& Dohme, Haar, Germany.

\section{References}

1 Itani KM, Wilson SE, Awad SS, et al: Ertapenem versus cefotetan prophylaxis in elective colorectal surgery. N Engl J Med 2006; 355:2640-2651.

-2 Barker KF: Antibiotic resistance: a current perspective. Br J Clin Pharmacol 1999;48: 109-124.

-3 Wiseman LR, Wagstaff AJ, Brogden RN, et al: Meronem. A review of its antibacterial activity, pharmacokinetic properties and clinical efficacy. Drugs 1995;50:73-101.

$\checkmark 4$ Cunha BA: Ertapenem. A review of its microbiologic, pharmacokinetic and clinical aspects. Drugs Today 2002;38:195-213.

$\checkmark 5$ Majumdar A, Musson DG, Birk KL, et al: Pharmacokinetics of ertapenem in healthy young volunteers. Antimicrob Agents Chemother 2002;46:3506-3511.

6 Wittau M, Wagner E, Kaever V, Koal T, Henne-Bruns D, Isenmann R: Intraabdominal tissue concentration of ertapenem. J Antimicrob Chemother 2006;57:312-316.

7 Laethem T, De Lepeleire I, McCrea J, et al: Tissue penetration by ertapenem, a parenteral carbapenem administered once daily, in suction-induced skin blister fluid in healthy young volunteers. Antimicrob Agents Chemother 2003;47:1439-1442.

$\checkmark 8$ Burkhardt O, Majcher-Peszynska J, Borner $\mathrm{K}$, et al: Penetration of ertapenem into different pulmonary compartments of patients undergoing lung surgery. J Clin Pharmacol 2005;45:659-665.

9 Burkhardt O, Brunner M, Schmidt S, Grant M, Tang Y, Derendorf H: Penetration of ertapenem into skeletal muscle and subcutaneous adipose tissue in healthy volunteers measured by in vivo microdialysis. J Antimicrob Chemother 2006;58:632-636.

$\checkmark 10$ Craig WA: Pharmacokinetic/pharmacodynamic parameters: rationale for antibacterial dosing of mice and men. Clin Infect Dis 1998;26:1-12.

11 Nix DE, Majumdar AK, DiNubile MJ: Pharmacokinetics and pharmacodynamics of ertapenem: an overview for clinicians. J Antimicrob Chemother 2004;53(suppl 2):ii23ii28.
12 Ambrose PG, Bhavnani MS, Rubino CM, Louie A, Gumbo T, Forrest A, Drusano GL: Pharmacokinetics-pharmacodynamics of antimicrobial therapy: it's not just for mice anymore. Clin Infect Dis 2007;44:79-86.

13 Bulitta JB, Landersdorfer CB, Forrest A, Brown SV, Neely MN, Tsuji BT, Louie A: Relevance of pharmacokinetic and pharmacodynamic modelling to clinical care of critically ill patients. Curr Pharm Biotechnol 2011, Epub ahead of print.

14 Chen MA, Nafziger N, Drusano GL, Ma L, Bertino JS Jr: Comparative pharmacokinetics and pharmacodynamic target attainment of ertapenem in normal-weight, obese, and extremely obese adults. Antimicrob Agents Chemother 2006;50:1222-1227.

15 Burkhardt O, Kumar V, Katterwe D, Majcher-Peszynska J, Drewelow B, Derendorf H, Welte T: Ertapenem in critically ill patients with early-onset ventilator-associated pneumonia: pharmacokinetics with special consideration of free-drug concentration. J Antimicrob Chemother 2007;59:277-284.

16 Wong B K, Bruhin BJ, Lin JH: Dose-dependent plasma clearance of MK-826, a carbapenem antibiotic, arising from concentration-dependent plasma protein binding in rats and monkeys. J Pharm Sci 1999;88:277280.

17 Koal T, Deters M, Resch K, Kaever V: Quantification of the carbapenem antibiotic ertapenem in human plasma by a validated liquid chromatography - mass spectrometry method. Clin Chim Acta 2006;364:239-245.

18 Waters NJ, Jones R, Williams G, Sohal B: Validation of a rapid equilibrium dialysis approach for the measurement of plasma protein binding. J Pharm Sci 2008;97:45864595.

19 Brendel K, Comets E, Laffont C, Laveille C, Mentre F: Metrics for external model evaluation with an application to the population pharmacokinetics of gliclazide. Pharm Res 2006;23:2036-2049.
20 Bulitta JB, Duffull SB, Kinzig-Schippers M, Holzgrabe U, Stephan U, Drusano GL, Sörgel F: Systematic comparison of the population pharmacokinetics and pharmacodynamics of piperacillin in cystic fibrosis patients and healthy volunteers. Antimicrob Agents Chemother 2007;51:2497-2507.

21 Anderson BJ, Holford NH: Mechanismbased concepts of size and maturity in pharmacokinetics. Annu Rev Pharmacol Toxicol 2008;48:303-332.

22 West GB, Brown JH, Enquist BJ: The fourth dimension of life: fractal geometry and allometric scaling of organisms. Science 1999; 284:1677-1679.

23 Bulitta JB, Bingolbali A, Shin BS, Landersdorfer CB: Development of a new pre- and post-processing tool (SADAPT-TRAN) for nonlinear mixed-effects modeling in SADAPT. AAPS J 2011;13:201-211.

24 Bulitta JB, Landersdorfer CB: Performance and robustness of the Monte Carlo importance sampling algorithm using parallelized S-ADAPT for basic and complex mechanistic models. AAPS J 2011;13:212-226.

25 Landersdorfer CB, Kinzig M, Hennig FF, Bulitta JB, Holzgrabe U, Drusano GL, Sörgel F, Gusinde J: Penetration of moxifloxacin into bone evaluated by Monte Carlo simulation. Antimicrob Agents Chemother 2009;53: 2074-2081.

26 Prokocimer P, Bien P, Surber J, Mehra P, DeAnda C, Bulitta JB, Corey GR: Phase 2, randomized, double-blind, dose-ranging study evaluating the safety, tolerability, population pharmacokinetics, and efficacy of oral torezolid phosphate in patients with complicated skin and skin structure infections. Antimicrob Agents Chemother 2011;55:583592.

27 Beal SL, Sheiner LB, Boeckmann AJ, Bauer RJ: NONMEM User's Guides (1989-2009). Ellicott City, Icon Development Solutions, 2009

28 Drusano GL: Antimicrobial pharmacodynamics: critical interactions of 'bug and drug'. Nat Rev Microbiol 2004;2:289-300. 
29 Frasca A, Marchand S, Petitpas F, et al: Pharmacokinetics of ertapenem following intravenous and subcutaneous infusion in patients. Antimicrob Agents Chemother 2010; 54:924-926.

-30 Burkhardt O, Kumar V, Schmidt S, Kielstein JT, Welte T, Derendorf H: Underdosing of ertapenem in critically ill patients with pneumonia confirmed by Monte Carlo simulations. Int J Antimicrob Agents 2010;35:96-97.

-31 Pletz MW, Rau M, Bulitta JB, De Roux A, Burkhardt O, Kruse G, Kurowski M, Nord $\mathrm{CE}$, Lode H: Ertapenem pharmacokinetics and impact on intestinal microflora, in comparison to those of ceftriaxone, after multiple dosing in male and female volunteers. Antimicrob Agents Chemother 2004;48: 3765-3772.

>32 Boselli E, Breilh D, Saux MC, Gordien JB, Allaouchiche B: Pharmacokinetics and lung concentrations of ertapenem in patients with ventilator-associated pneumonia. Intensive Care Med 2006, 32:2059-2062.
33 Brink AJ, Richards GA, Schillack V, Kiem S, Schentag J. Pharmacokinetics of once-daily dosing of ertapenem in critically ill patients with severe sepsis. Int J Antimicrob Agents 2009;33:432-436.

34 Ulldemolins M, Roberts JA, Rello J, Paterson DL, Lipman J: The effects of hypoalbuminaemia on optimizing antibacterial dosing in critically ill patients. Clin Pharmacokinet 2011;50:99-110.

35 Burkhardt O, Hafer C, Langhoff A, Kaever V, Kumar V, Welte T, Haller H, Fliser D, Kielstein JT: Pharmacokinetics of ertapenem in critically ill patients with acute renal failure undergoing extended daily dialysis. Nephrol Dial Transplant 2009;24:267-271.

36 Solomkin JS, Yellin AE, Rotstein OD, et al: Ertapenem versus piperacillin/tazobactam in the treatment of complicated intraabdominal infections: results of a double-blind, randomized comparative phase III trial. Ann Surg 2003;237:235-245.
37 Yellin AE, Hassett JM, Fernandez A, et al: Ertapenem monotherapy versus combined therapy with ceftriaxone plus metronidazole for treatment of complicated intraabdominal infections in adults. Int J Antimicrob Agents 2002;20:165-167.

38 Schug-Pass C, Geers P, Hügel O, et al: Prospective randomized trial comparing shortterm antibiotic therapy versus standard therapy for acute uncomplicated sigmoid diverticulitis. Int J Colorectal Dis 2010;395: 569-574.

-39 Kunz AN, Brook I: Emerging resistant Gram-negative aerobic bacilli in hospital-acquired infections. Chemotherapy 2010;56: 492-500.

40 Neonakis IK, Samonis G, Messaritakis H, et al: Resistance status and evolution trends of Klebsiella pneumoniae isolates in a university hospital in Greece: ineffectiveness of carbapenems and increasing resistance to colistin. Chemotherapy 2010;56:448-452. 